\title{
IIlicium verum Mediated Preparation of Zinc oxide Nanoparticles: XRD, Spectral and Microscopic Analysis
}

\author{
M. KALAIMATHI ${ }^{*}$, A. MAHESHWARAN 1 , K. HARIHARAN 1 , \\ B. POOVARASAN ${ }^{1}$ and P. CHANDRU ${ }^{1}$
}

\begin{abstract}
${ }^{1}$ Karpagam Academy of Higher Education, Pollachi Main road, Coimbatore- 641021, India. *Corresponding author E-mail: m.kalaimathi15@gmail.com
\end{abstract}

http://dx.doi.org/10.13005/ojc/370419

(Received: June 06, 2021; Accepted: August 02, 2021)

\begin{abstract}
The zinc oxide nanoparticles were successfully synthesized using zinc nitrate as the precursor and extract of Illicium verum was used as the reducing and stabilizing agent. Synthesized zinc oxide particles in nano size were characterized by FT-IR, Ultraviolet-Visible SEM \& XRD techniques. The formed nanoparticles were confirmed as zinc oxide nanoparticles by UV-Visible, FT-IR spectroscopic techniques. XRD data gave the results regarding structure and size of the prepared nano-sized particles. According to the results of XRD, the size was calculated as $27.01 \mathrm{~nm}$. SEM analysis results sphere and flake like shape and morphology of zinc oxide nanoparticles.
\end{abstract}

Keywords: Nanoparticles, zinc oxide, Illicium verum, Green synthesis, SEM.

\section{INTRODUCTION}

Nanotechnology is a rapidly growing interdisciplinary field with tremendous applications and having exciting and unique properties. It involves particles with 1-100 $\mathrm{nm}$ size and used in more applications oriented studies ${ }^{1,2}$. It is considered as center point for the researchers in chemical, biological, physical and engineering fields. Nowadays environmental pollution such as water, air, soil and noise pollutions is the major problem existing on earth. Nanotechnology serves an effective tool in the eradication of such pollution. The main sources of these kinds of pollution are created by the excretion of industrial wastes and effluents. It may be solid waste or liquid or gaseous matters ${ }^{3,4}$. From various industries, effluents were discharged into the water bodies and creating water pollution. So on searching techniques to decompose the effluents before reaching water bodies, Fujishima and Honda reported that varieties of semiconductors like $\mathrm{ZnS}$, Zinc oxide, $\mathrm{TiO}_{2}, \mathrm{ZrO}_{2}, \mathrm{CuO}, \mathrm{CdS}, \mathrm{NiO}$, $\mathrm{Cu}_{2} \mathrm{O}, \mathrm{Ta}_{2} \mathrm{O}_{5}, \mathrm{ZnFe}_{2} \mathrm{O}_{4}$ were used to decompose pollutants in water ${ }^{5-23}$. Among these semiconductors Zinc oxide is considered as important semiconductor because of its non-hazardous and economically favorable characteristics. zinc oxide is abundantly present in nature and has attractive characteristics related to many applications ${ }^{24-25}$. Approximately $45 \%$ of synthetically prepared zinc oxide was used as additive in rubber vulcanization ${ }^{26}$. In this view zinc oxide with different crystal structure wurzite, zinc

This is an Open Access article licensed under a Creative Commons license: Attribution 4.0 International (CC- BY). Published by Oriental Scientific Publishing Company @ 2018

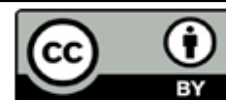


blende, rock salt and band gap value of $3.1-3.3 \mathrm{eV}$ is used in many fields ${ }^{27}$. Zinc oxide nanoparticles are used in food packaging, sunscreens, paints and as coating materials $\mathrm{s}^{28}$. Antimicrobial agents prepared from organic compounds are mostly sensitive to temperature and pressure. Most of the antimicrobial agents are toxic and produce unexpected side effects due to their bulky groups ${ }^{29-33}$. Based on particles in various parameters, the biological and pharmaceutical field is developed ${ }^{1,34}$. That is why we need to go for inorganic compounds as antimicrobial agents, especially nano-sized inorganic metal oxides. The role of inorganic metal nanoparticles was not disturbed by high temperature and pressure due to their long shelf-life. Immeasurable sources are available in nature, which is useful for many biological reactions ${ }^{35-36}$. In present condition, scientists have discovered various methods to prepare nanoparticles; they were financially flexible to us. Nowadays, major research is developing on green synthesis of nanoparticles using organisms. Especially plant species are used in large-scale, biosynthesis of nanoparticles ${ }^{37-39}$. Various parts of the plants are used for the preparation of nanoparticles. Phytochemicals present in the plants are acting as the reducing, capping and stabilizing agents ${ }^{40-41}$. In the preparation of nano-sized particles in green method, route using salts such as nitrates, chlorates and sulfates of metals as the starting materials. Metabolites and proteins in biological systems acting as reducing agent and reduces the inorganic metal ions into metal nanoparticles ${ }^{42}$. Due to environmental friendliness, cost-effectiveness, biocompatibility and safety, nanoparticles were produced using microorganisms and plants through their reductive capacities. Polyphenols, carbohydrates, alkaloids, terpenoids play the main role in reducing metal ions and maintaining stability ${ }^{43}$.

Green synthesis is better than traditional methods, in the following aspects,

1) It is quite easy and needed short time.

2) We need not add chemicals as reducing agent plant based compounds act as reducing agent. 3) Inexpensive method ${ }^{44-45}$.

Some results are obtained by changing calcination temperature, concentrations, reaction conditions. V. A. Soares et al., prepared $\mathrm{ZnO}$ nanoparticles by in a greener way and depicted the nanoparticles by XRD, TEM and Raman spectroscopy.
The reported size was $18-89 \mathrm{~nm}$. They observed that when calcinations temperature increased, the band gap of $\mathrm{ZnO}$ nanoparticles was decreased ${ }^{46}$.

C. A. Soto Robles et al., synthesized $\mathrm{ZnO}$ nanoparticles using Hibiscus sabdariffa extract in various concentrations and studied the effect of concentration. When the concentration of extract increased the band gap value decreases from 2.96 to $2.77 \mathrm{eV}$ and destroyed the methylene blue for about $97 \%{ }^{47}$.

In 2019, Sarid Taghavi Fardood and his co-workers synthesized $\mathrm{ZnO}$ nanoparticles and used as the catalyst in organic coupling reactions. In 2019, Jejenija Osuntokun et al., prepared nanoparticles using broccoli and studied their photocatalytic activity. They followed two ways to synthesize $\mathrm{ZnO}$ nanoparticles. One is by adding broccoli, another one is without adding broccoli. They were characterized separately. The particle sizes obtained were $14 \mathrm{~nm}$ and $17 \mathrm{~nm}$ for broc-ZnO and $\mathrm{nb}-\mathrm{ZnO}$ respectively. $74 \%$ of dye was degraded by this synthesized $\mathrm{ZnO}$ nanoparticles ${ }^{48}$. Jorge Rodrigues et al., (2020) have been prepared $\mathrm{ZnO}, \mathrm{Ag}-\mathrm{ZnO}$ and $\mathrm{Pd}$ $\mathrm{ZnO}$ nanoparticles by co-precipitation method for photodegradation of textile effluents in the presence of UV-light. They have been found that the $\mathrm{ZnO}$ removed $100 \%$ of RB 19 and $91 \%$ of RB 21 over six hours ${ }^{49}$.

L.S. Reddy Yadav et al., (2019) have been synthesized silver-doped $\mathrm{ZnO}$ nanoparticles using turmeric root extract as a fuel. They have been investigated the structure and morphology of $\mathrm{Ag}-\mathrm{ZnO}$ nanoparticles using various analytical techniques such as UV-Vis spectroscopy, Raman spectroscopy, XRD, XPS, FT-IR, SEM and TEM. They have been used $\mathrm{Ag}-\mathrm{ZnO}$ nanocatalyst for hydrogen generation and formylation ${ }^{50}$.

In our research, we used Illicium verum (Star Anise). The major components present in Illicium verum are flavanoids and polyphenols. Linalool, quercetin, anethole, shickimic acid, gallic acid, limonene are present in Illicium verum ${ }^{51-54}$. Even though more number of methods available on synthesis of zinc oxide nanoparticles we are reporting the green synthesis of zinc oxide nanoparticles using Illicium verum in this article. The synthesized zinc oxide nanoparticles were characterized by various spectroscopic, microscopic techniques and XRD. 


\section{EXPERIMENTAL}

\section{Materials}

Commercially available Illicium verum was purchased and played the role as reducing and stabilizing agent. The purest form of zinc nitrate $(\approx 99 \%)$ and $\mathrm{NaOH}(\approx 98 \%)$ were got from SigmaAldrich chemicals. The chemicals were diluted to preferred concentrations by adding deionized water.

\section{Illicium verum mediated Preparation of Zinc oxide particles in nano size}

$25 \mathrm{~g}$ of thoroughly powdered Illicium verum (Star Anise) was weighed and dissolved in $150 \mathrm{~mL}$ of deionized water. The mixture was refluxed for about 45 minutes. The mixture was allowed to cool and separated in cold condition. $0.1 \mathrm{~N}$ solution of zinc nitrate was prepared for about $100 \mathrm{~mL}$. $20 \mathrm{~mL}$ of the plant extract was mixed to $100 \mathrm{~mL}$ of $0.1 \mathrm{~N}$ zinc nitrate solution. To the above mixture, $2 \mathrm{M}$ sodium hydroxide was added in drops to increase precipitation as well as $\mathrm{pH}$ maintenance. The whole mixture was kept in magnetic stirrer for about $2 \mathrm{~h}$ till the color change of the solution. The precipitate was separated using Whatmann No. 1 and dried at $100^{\circ} \mathrm{C}$ to obtain Zinc oxide nanoparticles ${ }^{55-56}$.

\section{Characterization of zinc oxide nanoparticles prepared by using IIlicium verum}

The prepared zinc oxide nanoparticles were characterized by different techniques. The functional groups present were analyzed using FT-IR spectroscopy. The IR spectrum was recorded in $\mathrm{KBr}$ disc on a Shimadzu IR spectrophotometer in the range $200-4000 \mathrm{~cm}^{-1}$ in Amrita College, Coimbatore. The percentage transmission against wave number was recorded. The interpretation of the infrared spectrum of any substance under study can be done by taking a substance with the known group frequencies. The electronic spectrum has been mostly used to depict the semiconductor nanoparticles. When the particle size decreased, absorption wavelength shifted to lower wavelength automatically band gap will be increased. The electronic spectrum is recorded in acetone solvent by Shimadzu 1800 UV double beam spectrometer in Jayaraj Annapackiam College for Women, Theni. $X$-Ray diffraction was used to know the crystal structure of samples. It was recorded in Jayaraj Annapackiam College for Women, Theni. Scanning Electron Microscopy (SEM) was used to study the morphology of zinc oxide nanoparticles. The SEM is recorded by JEQL Model 6390 computer-controlled microscope in Karunya University, Coimbatore.

\section{RESULTS AND DISCUSSION}

\section{UV-Visible spectral Analysis}

The UV-Visible spectroscopy was adapted to identify the generation of zinc oxide nanoparticles. An absorption band appeared in $375 \mathrm{~nm}$ is formal peak of zinc oxide nanoparticles is shown in Fig. 1. It confirms the effective formation of Zinc oxide nanoparticles using Illicium verum ${ }^{57}$.

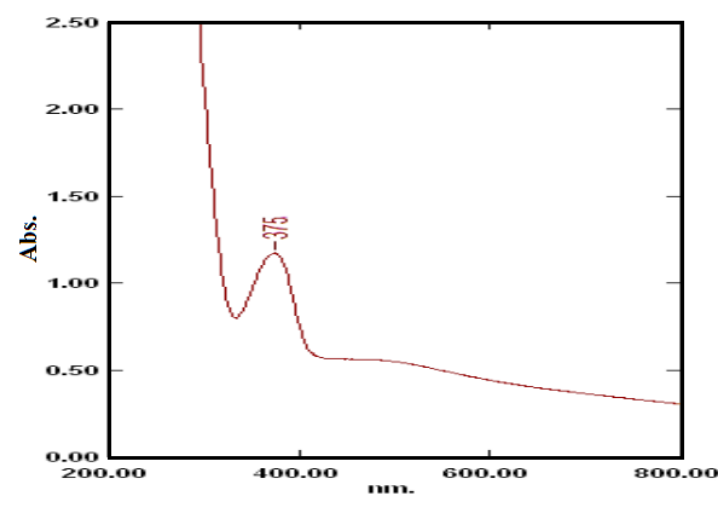

Fig. 1. The electronic spectrum of zinc oxide nanoparticle (Illicium veerum)

\section{FT-IR spectral Analysis}

The FT-IR spectrum of zinc oxide nanoparticles synthesized from Illicium verum is depicted in Fig. 2. FT-IR spectrum of zinc oxide nanoparticles showed specific stretching vibrations. The stretching frequency observed in $544 \mathrm{~cm}^{-1}$ indicated an effective formation of zinc oxide nanoparticles ${ }^{58}$. The broad range in $3732 \mathrm{~cm}^{-1}$ reveals stretching frequency of $\mathrm{O}-\mathrm{H}$ group. The vibrational frequencies in the range of $836-2527 \mathrm{~cm}^{-1}$ will be attributed to flavonoids and polyphenols exist in Illicium verum solution.

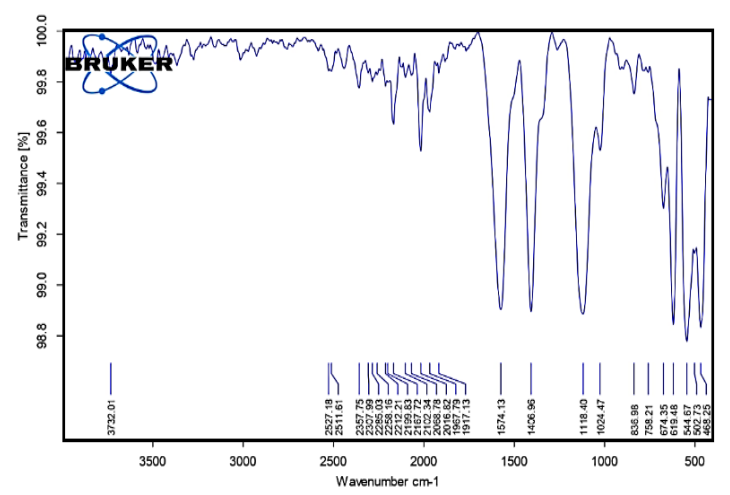

Fig. 2. FT-IR spectrum of zinc oxide nanoparticle (Illicium verum) 


\section{XRD studies}

The catalytic and crystal structures were studied by X-ray diffraction patterns. X-ray diffraction patterns of the synthesized zinc oxide nanoparticles show strong diffraction peaks at $31.67^{\circ}, 34.31^{\circ}$, $36.17^{\circ}, 47.44^{\circ}, 56.46^{\circ}, 62.62^{\circ}, 66.21^{\circ}, 67.70^{\circ}, 72.42^{\circ}$, $77.04^{\circ}$ corresponds to $100,002,101,102,110,103$, $200,112,201,004,202$ hexagonal crystal planes. The particle size was found to be $27.01 \mathrm{~nm}$. From peak values and corresponding lattice planes, hexagonal wurzite structure of zinc oxide nanoparticles was confirmed. It is further affirmed by the JCPDS card No. $36-1451^{47,59}$. Debye-Scherrer equation used to calculate particle size is given below

\section{$\mathrm{D}=\mathrm{K} \lambda / \beta \cos \theta$}

$D$-size of the nanoparticles.

$\lambda$-wavelength of incident beam.

$\beta$-full width for half maximum.

$\theta$-diffraction angle.

The constant $\mathrm{K}$ is shape factor. $\lambda=1.5406$ $A^{\circ}: K=0.94$. Using this equation, the calculated particle size is $27.01 \mathrm{~nm}$. The XRD pattern is represented in Figure 3.

\section{SEM Analysis}

Using Scanning Electron Microscopy, the structure and morphology were determined. The
SEM image of zinc oxide nanoparticles synthesized from Illicium verum exhibits sphere and flake like aggregates is represented in Fig. 4. The results of green synthesis of nanoparticles using various plant sources are tabulated in Table 1 and compared the obtained results with them.

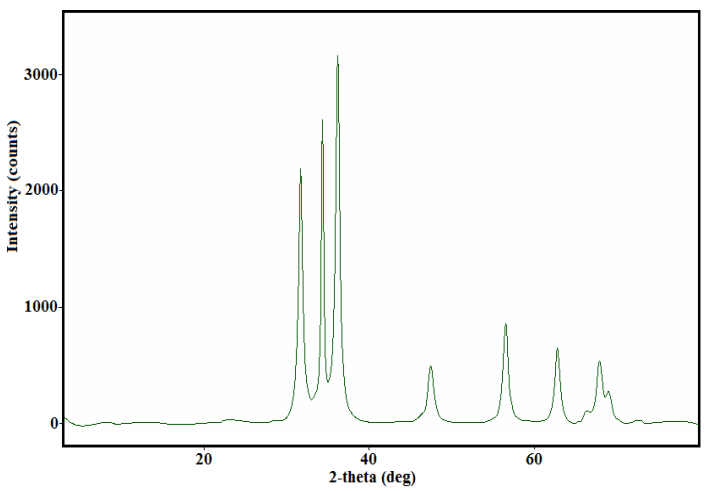

Fig. 3. XRD Spectrum of zinc oxide nanoparticle (Illicium verum)

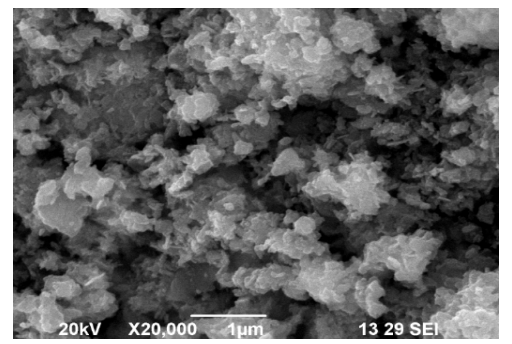

Fig. 4. Scanning Electron Microscopic image of zinc oxide nanoparticles (IIlicium verum)

Table 1: Comparative results of green synthesis of $\mathrm{ZnO}$ noparticles using various plant parts

\begin{tabular}{clcc}
\hline S.No. & Plant (family) & Size (nm) & Shape \\
\hline 1. & Azadirachta indica (Meliaceae) & 18 & spherical \\
2. & Agathosma beulina (Rutaceae) & 15.8 & Quasi-spherical agglomerates \\
3. & Aloe Vera (Liliaceae) & $8-20$ & Spherical, oval \\
4. & Coptidis rhizoma (Ranunculaceae) & $2.9-25.2$ & Spherical, rod shaped \\
5. & Phyllanthus niruri (Phyllanthaceae) & 25.61 & Hexagonal wurzite \\
6. & Pongamia pinnata (Legumes) & 26 & Spherical, hexagonal \\
7. & Trifolium pratense (Legumes) & $60-70$ & spherical \\
8. & Rosa canina (Rosaceae) & 13.3 & spherical \\
9. & Solanum nigrum (Solanaceae) & $20-30$ & Wurzite hexagonal \\
10. & Illicium verum (Schisandraceae) & 27.01 & Sphere and flake like structure \\
\hline
\end{tabular}

\section{CONCLUSION}

Zinc oxide nanoparticles have been effectively synthesized using Illicium verum and characterized using different spectroscopic and microscopic techniques. The UV-Visible spectrum showed functional band in $375 \mathrm{~nm}$ region. FT-IR spectroscopy exhibited a characteristic peak at 544 $\mathrm{cm}^{-1}$ responsible for $\mathrm{ZnO}$. From spectroscopic results, the formation of $\mathrm{ZnO}$ nanoparticles was depicted. SEM and XRD analysis gave the morphology and size of the nanoparticles. The results represented the formation of sphere and flake like zinc oxide nanoparticles in the size of $27.01 \mathrm{~nm}$. The obtained results were compared with the earlier studies and confirmed that the results were acceptable one. 


\section{ACKNOWLEDGEMENT}

I thank the management of Karpagam Academy of Higher Education for their support and encouragement to do this project in a successful manner.

\section{Conflict of Interest}

No conflict of interest.

\section{REFERENCES}

1. Singh R. P.; Kasariya K.; Singhal G.; J. Nanoparticle Res., 2011, 13(7), 2981-2988.

2. Aswani M. T.; Pavan Kumar M. V.; Binu Varghesel, AIP Conference Proceedings. 2020, 02001, 2263.

3. Siripireddy B.; Mandal B. K.; Adv. Powder Technol., 2017, 28, 785-797.

4. $\quad$ Lee K. M.; Lai C. W.; Ngai K. S.; Juan J. C.; Water Res., 2016, 88, 428-448.

5. Lu M. -Y.; Lu M.-P.; Chung Y.-A.; Chen M.-J.; Wang Z.L.; Chen L.-J.; J. Phys. Chem. C., 2009, 113, 12878-12882.

6. Nagaraju G.; Nagabhushana H.; Suresh D.; Anupama C.; Raghu G. K.; Sharma S.C.; Cerum. Int., 2017, 351.

7. Singh J.; atthi A.; Rawat M.; Kumar V.; Kim K.; Composites B. In Press. Compos Part B., 2019, 165, 823

8. $\quad$ Zhang Q.; GQ L. A.; Zhao; Li Z.; Xu X.; Morphology-modulations of $\mathrm{iO} 2$ nanostructures for enhanced photocatalytic performance. Appl. Surf. Sci., 2015, 332, 224-228.

9. Schneider J.; Matsuoka M.; Takeuchi M.; Zhang J.; Horiguchi Y.; Anpo M.; Bahnemann D. W.; Chem. ev., 2014, 114, 9919-9986.

10. Safajou H.; Khojasteh H.; Salavati-niasari M.; Khojasteh H.; Nanocomposites., 2017, DOI: doi.or/10.1016/j.jcis.2017.03.078.

11. Zinatloo-ajabshir S.; Salavati-niasari M.; J. Mol. Liq., 2016, 216, 545-551.

12. Xiong S.; Xi B.; Qian Y.; J. phys. Chem., 2010, C114,14029-14035.

13. Saravanan R.: Karthikeyan S.; Gupta V.K.; Sekaran G.; Narayanan V.; Stephen A.; Mater. Sci. Eng. C., 2013, 3391-98.

14. Salavati-niasari M.; Loghman-estarki M. R.; Davar F.; Inorganica Chimica Acta., 2009, 362, 3677-3683.

15. Motahari F.; Mozdianfard M.R.; Soovifand F.; Salavati-Niasari M.; RSC Adv., 2014, DOI: doi.or/10.1039/c4ra0 2697g.

16. Alvarez S.; Ye S.; Flowers P. F.; Wiley B. J.; Chem. Mater., 2015, 27, 570-573.

17. Deng X.; Zhang Q.; Zhao Q.; Ma L.; Ding M.; Xu X.; Nanoscale Res. Lett., 2015, 10, 8.
18. Nagaraju G.; Karthik K.; Shashank M.; Microchem. J., 2019, 147, 749-754.

19. Ghiyasiyan-arani M.; Salavati-niasari M.; Naseh S.; Ultrason-Sonochem., 2017, DOI: doi.org/10.1016/j.ultsonch.2017.05.025.

20. Salavati-niasari M.; Soofivand F.; Sobhaninasab A.; Shokouriarani M.; Adv. Power Technol., 2016, DOI: doi.org/10.10116/j.apt. 2016.07.018.

21. Hosseinpour-mashkani S. M.; Mohandes F.; Salavati- niasari M.; Venkateswara- rao K.; Mater. Res. Bull., 2012, 47, 3148-3159.

22. Naik M. M.; Naik H. S. B.; Nagaraju G.; Vinuth M.; Naika H.R.; Vinu K.; Microchem. J., 2019, DOI: doi.org/10.1016/j.micro c.2019.02.059.

23. Eley C.; Li T.; Liao F.; Fairclough S. M.; Smith J. M.; Smith G.; Tsang S. C. E.; Angew. Chem. Int. Ed., 2014, 53, 7838-7842.

24. Pivin J.C.; Socol G.; Mihailescu I.; Berthet P.; Singh F.; Patel M. K.; Thin Solid Films., 2008, 517, 916.

25. Sato K.; Katayama H. - Yoshida;, Jpn J. Appl. Phys., 2000, 39, 555.

26. Engles H. W.; Weidenhaupt H. J.; Abele M.; Pieroth M. and Hofmann W.; Ullmaan's Encyclopedia of Industrial Chemistry., 2001, 6 th ed.

27. You A.; Be M. A. Y. and In I.; J. Appl. Phy., 1998, 83(10), 5447.

28. Franklin N. M.; Rogers N. J.;Apte S. C.; Environ. Sci. Technol., 2007, 41(24), 8484-8490.

29. Hajipour M. J.; Fromm K.M.; Askharran A. A.; DE Aberasturi D. J.; Larramendi I. R.; Lu J.; Serpooshan V.; Parak W. J.; Mahmoudi M.; Trends Biotechno., 2012, 30, 499-511.

30. Mayn/ard A. D.; Warheit D. B.; Philibert M. A.; Nanotxicology and Beyaond. Toxicol. Sci., 2011, 120.

31. Ji J.; Zhang W.; J. Biomed. Mater. Res., 2008, 88, 448-453.

32. Goharshadi E. K.; Ding Y.; Jorabchi M. N.; Nancarrow P.; Ultrason. Sonochem., 2009, 16, 120-123.

33. Sharifalhoseini Z.; Entezari M. H.; Jalal R.; Ultrason. Sonochem., 2015, 27, 466-473. 
34. Ztu O.; Rk B. Y.; Caryologia Int. J. Cytol. Cytosystematics Cytogenet., 2019, 72(1), 29-43.

35. Sultana S.; Mohammad R.; Khan Z.; Umar K.; Ahmed A. S.; Shahadat M.; J. Mol. Struct., 2015, 1098, 393-399.

36. Suresh D.; Nethravathi P.C.; Rajanaika U. H.; Nagabhushana H.; Sharma S. C.; Mater. Sci. semicond. process., 2015, 31, 446-454.

37. Taghavi Fardood S.; Ramazani A.; Joo S. W.; J. Appl. Chem. Res., 2017, 11, 19.

38. Taghavi Fardood S.; Ramazani A.; Joo S. W.; J. Appl. Chem. Res., 2018, 12, 8.

39. Halimi M.; Nasrabadi M.; Soleamani N.; Rouhani N.; Asian J. Nano. Mat., 2018, 1, 19.

40. Oza G.; Reyes-Calderon A.; Mewada A.; Arriaga L. G.; Cabrera G. B.; Luna D. E.; Iqbal H. M.; Sharon M.; Sharma A.; Journal of Materials Science., 2020, 1-22.

41. Ghotekar S.; Pansambal S.; Pawar S. P.; Pagar T.; Oza R.; Bangale S.; SN Applied Sciences., 2019, 1, 1342.

42. Makarov V.V.; Love A. J.; Sinitsyna O. V.; Green Chem., 2013, 13(10), 2638-2650.

43. Aswathy Aromal S.; Philip D.; Spectrochim Acta A Mol Biomol Spectrosc., 2012, 97, 1-5.

44. Raveendran P.; Fu J.; Wallen S. L.; J. Am. Chem. Soc., 2003, 125(46), 13940-13941.

45. Soto-Robles C. A.; Nava O. J.; Vilchis- Nestor A. R.; J. Mater. Sci.mater Electron., 2018, 29, 3722-3729.

46. Soares V. A.; Xavier M. J. S.; Rodrigues E. S.; Oliveira C. A.; Farias P.M.A.; Stingl A.; Ferreira N. S.; Silva M. S.; Materials Letters., 2019.

47. Soto-Robles C.A.; Luque P. A.; Gomez-
Gutierrez C. M.; Nava O.; Vilchis-Nestor A. R.; Lugo-Medina E.; Ranjithkumar R.; CastroBeltran A.; Results in physics., 2019.

48. Jejenija Osuntokun, Damian C.Onwudiwe \& Eno E. Ebenso, Green chemistry Letters and Reviews., 2019, 12(4), 444-457.

49. Sy L. K.; Brown G. D.; J. Nat. prod., 1998, 61(8), 987-992.

50. Tuan D. Q.; llangantileke S. G.; J. Food Eng., 1997, 31, 47-57.

51. Mubayi A.; Chatterji S.; Rai P. M.; Watal G.; Adv. Mat. Let., 2012, 13(6), 519-525.

52. Jannatul Ferrdous Rumkyl; Zainal Abedin; Hafizur Rahman; Ali Hossain; Environmental Treatment of dyes., 2013.

53. Kampf R.; Steinegger E.; Acta Helv., 1974, 49(2), 87-93.

54. Perry L. M.; Medicinal plants of East and Southeast Asia, 1980, 180.

55. Lu J.; Batjikh I.; Hurh J.; Han Y.; Ali H.; Mathiyalagan R.; Ling C.; Ahn J. C.; Yang D. C.; Optik (Stuttg), 2019, 182, 980-985.

56. Fowsiya J., Madhumitha G., Al-Dhabi N. A., Arasu M. V., J. Photochem. Photobiol. B Biol., 2016, 395-401.

57. Ullah R.; Dutta J.; J. Hazard. Mater., 2008, 156(1-3), 194-200.

58. Joel C. and Sheik Muhideen Badhusha M.; Scholars Research Library Der Pharmacia Lettr., 2016, 8(11), 218-223.

59. Jiya Mary George M. T.; Aswani M. V.; Pavan Kumar, Binu Varghese, AIP Conference Proceedings., 2020, 2263, 020001, DOI: doi. org/10.1063/5.0017250. 